\title{
INBOUND MARKETING EM BIBLIOTECAS UNIVERSITÁRIAS: NOVAS FORMAS DE MEDIAÇÃO DA INFORMAÇÃO
}

\section{INBOUND MARKETING IN LIBRARIES: NEW FORMS OF INFORMATION MEDIATION}

\author{
Janaina Carla Ferreiraa \\ João Arlindo dos Santos Netob
}

\begin{abstract}
RESUMO
Objetivo: Discutir como as bibliotecas universitárias podem adotar o inbound marketing para potencializar a mediação da informação. Metodologia: A pesquisa é de natureza básica e tipologia exploratória, emprega a abordagem qualitativa e segue 0 delineamento bibliográfico a partir da literatura especializada em Ciência da Informação e Marketing, publicada nas principais bases de dados e fontes de informação à saber: Portal de Periódicos da CAPES, Base de Dados em Ciência da Informação (BRAPCI), Scielo e Google Acadêmico. Resultados: As estratégias de inbound marketing subsidiam a interação das bibliotecas com seus usuários de forma mais direta e efetiva e também são importantes para a mediação da informação. Conclusões: Conhecer estratégias contemporâneas de marketing, como o inbound marketing, permitem a prospecção de novas formas de mediação da informação para potencializar os produtos e serviços informacionais das BUs.
\end{abstract}

Descritores: Marketing em bibliotecas. Inbound Marketing. Bibliotecas Universitárias. Mediação da informação.

\section{INTRODUÇÃO}

O marketing é um conceito oriundo do campo da Administração, mas é discutido em muitas disciplinas, como é o caso da Biblioteconomia e Ciência da Informação (Cl). Comumente associado a vendas e propagandas, o conceito de marketing sofreu profundas transformações e refere-se a um conjunto complexo teorias, ferramentas, tecnologias e recursos humanos que visam agregar valor a

\footnotetext{
a Graduada em Biblioteconomia pela Universidade Estadual de Londrina (UEL). E-mail: janainacbf@gmail.com.

b Doutor em Ciência da Informação pela Universidade Estadual Paulista (UNESP). Professor do Departamento de Ciência da Informação da Universidade Estadual de Londrina (UEL). E-mail: santosneto@uel.br.
} 
um produto/serviço e fidelizar clientes/consumidores.

Em um mercado competitivo, mesmo para organizações que não visam lucro monetário, o marketing se faz extremamente necessário para atrair e fidelizar usuários de uma organização independente do setor em que está inserida. Desse modo, abordagens teórico-práticas se fazem necessárias para que essas organizações acompanhem novas perspectivas e possam oferecer experiências significativas e marcantes aos seus usuários e clientes.

As Bibliotecas Universitárias (BUs) classificam-se no terceiro setor, já que são organizações que não visam lucro e não podem gerar prejuízo, no entanto, atuam na linha dos serviços informacionais e culturais, mas também na linha de entretenimento, visto que atualmente os equipamentos informacionais dispõem de variados serviços e produtos, em sua maioria gratuitos.

O público de uma BU tem se apresentado como cada vez mais exigente, sendo composto por discentes, docentes, pesquisadores, técnicos e comunidade externa. O dia a dia do mediador da informação nas BUs vai muito além da organização e do tratamento temático e descritivo do acervo e do atendimento ao usuário, visto que esse profissional também é responsável por atrair novos usuários/clientes e fidelizar os que já frequentam a unidade de informação. Impõe-se ao mediador, num contexto tecnológico e globalizado, a necessidade de planejar, estudar e aplicar estratégias que atraiam seu público em benefício dos resultados, que podem ser: aumento de frequência na unidade de informação; maior número de empréstimos; conhecimento dos serviços ofertados; sentimento de pertença; uso do e permanência no espaço físico; entre outros, que só serão obtidos por meio de estratégias resultantes de novas abordagens de marketing e protagonismo do bibliotecário.

O bibliotecário precisa ter como uma de suas técnicas a capacidade de conquistar o seu público-alvo para que a biblioteca não perca espaço para outras organizações - como museus, livrarias, portais de busca (Google, por exemplo) e, inclusive, outras bibliotecas. Quando se pensa na palavra "atração" no caso das bibliotecas, visualiza-se imediatamente o setor de marketing, principal responsável pelo planejamento e divulgação de serviços de uma organização.

O marketing, muito além das vendas e propagandas, almeja criar valores 
tangíveis e intangíveis para os clientes. Diferentemente de algumas organizações e negócios do mercado, as bibliotecas não visam lucro e, na maioria dos casos, não possuem investimento para comportar um setor de marketing. Dessa maneira, a responsabilidade em atrair novos usuários e satisfazer as necessidades dos mesmos com os serviços oferecidos pela unidade, fica totalmente a cargo dos bibliotecários e demais profissionais que atuam na biblioteca para a realização de estratégias de marketing com foco na criação de valor. Acredita-se que o bibliotecário também pode assumir este papel, sendo o protagonista no processo de cativar e fidelizar os usuários, desde que domine as abordagens teórico-práticas do marketing.

Deste modo, investiga-se as abordagens contemporâneas do marketing, mais especificamente o Inbound Marketing (conhecido como o "Novo Marketing"), para potencializar o uso dos serviços informacionais a partir da mediação da informação em BUs. O inbound marketing se baseia em planejamento estratégico de informação e conteúdo direcionado para o seu público, disseminando conteúdos de seu interesse em ferramentas web, como blogs, redes sociais, websites e campanhas de e-mails. A referida abordagem se destaca pela produção de conteúdo para potencializar o alcance de um negócio/serviço, logo, possibilitar para as BUs novas formas de mediação da informação. A partir de conteúdos atrativos e informativos mediados nas BUs, pode-se conquistar e cativar o usuário de forma sucinta e eficaz.

Ao investigar a produção científica brasileira sobre marketing na $\mathrm{Cl}$, Prado e Pinto (2018) identificaram que há uma forte relação em se associar marketing com a comunicação, divulgação e tecnologia em diferentes tipologias de bibliotecas e que raros são os textos que buscaram refletir sobre o conceito de maneira empírica, com contribuições e relações junto com a $\mathrm{Cl}$. Durante as quatro décadas analisadas, os autores apontam que a produção aumentou consideravelmente e muitas discutem o marketing voltado para a divulgação.

Muitas BUs já executam ações de marketing no âmbito digital, como o uso de redes sociais, blogs, e-mails, websites próprios para mediar a informação, no entanto, muitas dessas ações não geram resultados, isto é, não são eficazes. Talvez, isto se deva pela falta de investimento ou pela cultura organizacional 
mais arraigada nas bibliotecas, em que profissionais da informação ainda se prendem a um modelo de trabalho tradicional e tecnicista. Sobretudo, por ser uma organização do terceiro setor, mantida na maioria das vezes por outras organizações ou governo, não recebe nenhum investimento para esse fim e muitos desses profissionais se sentem impossibilitados e descapacitados para cumprir outras funções.

Assim, questiona-se como o bibliotecário pode, a partir do inbound marketing, adotar novas estratégias de mediação da informação sem comprometer o investimento financeiro das BUs. As estratégias de inbound marketing podem facilitar muito o processo de comunicação com os usuários. Para responder o referido questionamento, o objetivo deste texto consiste em discutir como as BUs podem adotar o inbound marketing para potencializar a mediação da informação.

O artigo é composto pela presente introdução, sucedida pelas seguintes seções: procedimentos metodológicos, revisão de literatura acompanhada dos resultados e discussões e, considerações finais.

\section{PROCEDIMENTOS METODOLÓGICOS}

A pesquisa é de natureza básica, pois objetiva gerar conhecimentos novos, úteis para o avanço da Ciência (SILVEIRA; CÓRDOVA, 2009). Sua tipologia é exploratória, já que proporciona maior proximidade com o problema para deixá-lo mais explícito ou até mesmo construir hipóteses (GIL, 2002).

Emprega a abordagem qualitativa, pois relaciona aspectos que não podem ser quantificados e analisa/discute fenômenos sociais e subjetivos (SILVEIRA; CÓRDOVA, 2009) que não podem ser traduzidos em números. Segue o delineamento bibliográfico (GIL, 2002) a partir da literatura especializada em $\mathrm{Cl}$ e Marketing publicada nas principais bases de dados e fontes de informação a saber: Portal de Periódicos da CAPES, Base de Dados em Ciência da Informação (BRAPCl), Scielo e Google Acadêmico.

As buscas foram realizadas nas fontes mencionadas, a partir de estratégias booleanas, com a combinação dos termos: marketing, inbound marketing, mediação da informação e bibliotecas, sem delimitação temporal e 
nos idiomas inglês e português. Foram considerados somente os resultados cujos termos incidissem no título e/ou palavras-chave das produções. O corpus bibliográfico pode ser visualizado no quadro a seguir.

Quadro 1 - Total de resultados encontrados

\begin{tabular}{|l|c|c|c|c|}
\hline FONTES DE INFORMAÇÃO & $\begin{array}{c}\text { Portal de } \\
\text { Periódicos } \\
\text { da CAPES }\end{array}$ & BRAPCI & Scielo & $\begin{array}{c}\text { Google } \\
\text { Acadêmico }\end{array}$ \\
\hline marketing AND biblioteca & 2.661 & 173 & 0 & 643 \\
\hline inbound marketing AND biblioteca & 0 & 0 & 0 & 0 \\
\hline $\begin{array}{l}\text { (mediação OR mediação da } \\
\text { inforação) AND marketing }\end{array}$ & 0 & 0 & 0 & 3 \\
\hline
\end{tabular}

Fonte: Resultados da pesquisa (2021).

A partir dos resultados obtidos, constatou-se que há muitos trabalhos sobre marketing em bibliotecas e poucos que relacionam a temática marketing e mediação. Destaca-se que não foi encontrado nenhum resultado a partir da busca sobre inbound marketing AND biblioteca. Portanto, evidencia-se o caráter inovador dessa pesquisa.

Desse modo, foram selecionados os textos que correspondem ao objetivo da presente pesquisa: discutir como as bibliotecas podem adotar o inbound marketing para potencializar a mediação da informação. Como critérios para seleção do corpus dentre o total obtido, levou-se em consideração o teor dos trabalhos e a sua aderência temática em relação ao objetivo do presente artigo. Os resultados da pesquisa são apresentados a seguir e estes se mesclam à revisão de literatura, visto que o artigo é teórico e de delineamento bibliográfico.

\section{MARKETING E INBOUND MARKETING EM BIBLIOTECAS}

O marketing foi considerado durante muito tempo como o setor responsável pela propaganda e venda de produtos. No entanto, de acordo com Kotler (1998), as estratégias de marketing também podem ser aplicadas a diferentes segmentos do mercado, como: serviços, eventos, experiências, pessoas, lugares, propriedades, organizações sem fins lucrativos, informações, entre outros. Em complemento ao exposto, segundo Las Casas (2007, p. 15) o marketing: 
[...] é a área do conhecimento que engloba todas as atividades concernentes às relações de troca, orientadas para a satisfação dos desejos e necessidades dos consumidores, visando alcançar determinados objetivos da organização ou indivíduo e considerando sempre o meio ambiente de atuação e o impacto que estas relações causam no bem-estar da sociedade.

A satisfação dos desejos e necessidades do consumidor é o foco principal do marketing, que não está relacionado somente às vendas e resultados para obter lucro. Considerado por Kotler e Keller (2006) como "[...] uma função organizacional e um conjunto de processos [...]" o setor de marketing é fundamental também para direcionar, planejar e executar ações que fortaleçam os objetivos da organização, para que ela conte sua história, transmita seus valores e se faça presente no mercado por meio dos processos de criação, comunicação e oferta para agregar valor para os seus consumidores.

O marketing, suas ações e novos conceitos - como o inbound marketing - serve para ir muito além de divulgar produtos e serviços, essas estratégias auxiliam também na comunicação e aproximação com usuários no âmbito digital. No entanto, persiste ainda o senso comum de que o marketing é apenas vendas e propagandas, entretanto, muitas organizações estão se atentando cada vez mais para a ideia de que o marketing contribui de inúmeras formas para o sucesso de um negócio, seja ele centrado em produtos ou serviços.

A base do marketing é o planejamento para o atendimento das necessidades e desejos dos consumidores, passando do ideal quantitativo (número de vendas) ao qualitativo (experiência e fidelização do usuário). Nesse sentido, ao pensar na satisfação dos usuários nas BUs, nota-se que a aplicação de estratégias bem planejadas de marketing é uma alternativa para substituir a padronização pela customização dos produtos e serviços, mudando como o trabalho do bibliotecário é feito da maneira tradicional.

Gabriel (2010), afirma que o consumidor/cliente, adquire um papel central no cenário do marketing atual e que esse poder realmente foi alavancado pela tecnologia digital e ferramentas da Web 2.0. Nesse cenário, as BUs necessitam se atualizar para acompanhar a sua comunidade na busca por informação, seja pelo conteúdo disposto no acervo como também pela informação que é disponibilizada através do meio digital. 
Unidades de informação como arquivos e bibliotecas, precisam estar atualizadas ao marketing na era digital, pois a informação chega de maneira muito mais rápida através da web, e a resposta dos usuários chega na mesma proporção. Nesta perspectiva, novas abordagens do marketing e comunicação se fazem necessárias, pois assim como todo o mercado, os modelos e definições de marketing também evoluíram e se aperfeiçoaram, visando atender diferentes ramos e setores do mundo do trabalho.

Como o foco desse artigo é abordar novas estratégias de marketing, mais especificamente o inbound marketing', discute-se na sequência essa abordagem.

A evolução do outbound marketing conhecido como "marketing tradicional" denominou-se como inbound marketing, ou também conhecido como "novo marketing". O outbound marketing é uma forma mais tradicional de estratégia de prospecção de clientes mais agressiva para as organizações. Caracteriza-se como um método de comunicação em massa, baseado em campanhas na televisão, materiais impressos, outdoors, telemarketing, entre outros. Atualmente, essa estratégia apresenta-se ineficaz para serviços informacionais, pois as pessoas possuem características e necessidades diferentes, além de estarem inseridas num contexto que dispõe de outros veículos de comunicação.

Caneca (2015) descreveu a origem do termo inbound marketing em 2005, por Brian Halligan, co-fundador da HubSpot, empresa norte-americana pioneira nas estratégias de mídia digital que desenvolveu a captação de dados em formulário na página inicial de um website. Popularizou-se a partir de 2009 e pode ser traduzido livremente como "marketing de atração" (RESULTADOS DIGITAIS, 2016).

Com a chegada da internet há mais de 25 anos, o marketing também evoluiu, e uma das estratégias em foco é o inbound marketing que está sendo cada vez mais discutido e aplicado às estratégias de marketing, exclusivamente no ambiente digital. Seu principal objetivo é atrair e fidelizar clientes por meio de

\footnotetext{
${ }^{1}$ Conhecido como o "Novo Marketing", visa potencializar o processo de atender as necessidades e desejos dos usuários que enxergam os serviços e procuram a informação de outra forma.
} 
conteúdos que interessam o público-alvo da organização. Segundo Varanda (2010), o inbound marketing tem como objetivo cativar e causar desejo e interesse ao consumidor, além de informar e solucionar as "dores"/dúvidas do cliente. Destaca-se também a possibilidade de, a partir do inbound marketing, os valores agregados aos serviços informacionais oferecidos pelas BUs sejam (re)conhecidos pela comunidade de usuários.

O Portal Resultados Digitais (2016) afirma que essa atração é conquistada através de conteúdos de qualidade que solucionem as principais dúvidas do seu público. Sendo a produção de conteúdo o principal combustível para o Inbound, é necessário que esse conteúdo seja de qualidade e que comunique com as pessoas certas. Porém, para oferecer conteúdo relevante a um público-alvo e se comunicar de maneira assertiva com seus clientes é necessário conhecê-lo muito bem, através da criação de uma (ou mais) persona.

Rocha, Rodrigues e Rodrigues (2013) acreditam que o monitoramento de acessos é importante para o estabelecimento de um planejamento de marketing digital em bibliotecas. Quando se fala em acessos no marketing digital, se refere a interação com o usuário no âmbito digital, seja pelos blogs e redes sociais das BUs. Esses acessos são as respostas do usuário ao trabalho do mediador para mensurar a variedade e eficácia dos serviços e produtos ofertados, essas respostas são dadas em números de interação como cliques em links do website e blog, e também dados de publicações em redes sociais como compartilhamento, curtidas e comentários dos usuários. Tais mensurações são indicadores de envolvimento e atenção dada aos conteúdos disponibilizados na web e que permitem a avaliação das ações de marketing visando a continuidade delas ou sua reformulação.

O inbound marketing é parte de uma metodologia completa de Marketing Digital, que tem como proposta estreitar o relacionamento entre organização e possíveis consumidores durante o processo de compra e conseguinte o aumento dos resultados (vendas) das organizações por meio de ações definidas. (TREVISAN; MONTEIRO, 2017, p. 12).

Quando o inbound marketing é bem executado torna a comunicação da instituição mais clara e objetiva, fazendo com que a mesma alcance seus objetivos, fortaleça a sua missão e seus valores, além de estreitar o 
relacionamento com os usuários a fim de identificar melhor as necessidades e saber realmente o que buscam.

As estratégias do inbound marketing - como conteúdo bem planejado em blogs, materiais educativos (e-books, infográficos, webinars), divulgação em mídia online, otimização para mecanismos de buscas, entre outros - devem estar alinhadas com o planejamento estratégico de marketing da biblioteca. O conteúdo, base das estratégias do inbound marketing, se faz necessário para que o profissional possa mediar a informação em ambientes digitais. A mediação da informação nas BUs por meio das redes e mídias sociais, websites e blogs, proporciona um ambiente participativo ao usuário, em que este último pode solucionar suas questões em tempo real e se comunicar com o mediador. Ressalta-se, novamente, a importância do conteúdo disponibilizado nas plataformas para atrair o usuário, pois aquele se caracteriza como principal fator de interferência na comunicação com este último.

Santos (2012, p. 18) enfatiza que "[...] o espaço virtual vem demonstrando ser um importante dispositivo para o processo de transmissão de informações, um veículo rápido e acessível para o provimento de respostas aos usuários." Partindo desse ponto de vista, reforça-se que a interação (síncrona ou assíncrona) entre o usuário e o bibliotecário em âmbito digital, por meio das ferramentas apropriadas, fortalece o que se aborda nesta comunicação: as novas formas de mediação da informação fundamentadas em práticas de inbound marketing. Ressalta-se que o protagonismo do bibliotecário em meio a um modelo de trabalho tradicional e sua habilidade em promover e dar visibilidade a uma instituição, são elementos primordiais para equipamentos informacionais que não possuem investimento financeiro para tal.

O inbound marketing acontece diretamente no ambiente digital, pois além de centralizar o maior número de pessoas conectadas, também é o local em que as pessoas compartilham suas opiniões e interesses em rede. Além disso, 0 inbound marketing:

[...] se diferencia das demais técnicas de marketing porque consiste em melhorar o negócio, e não correr atrás de clientes, sendo que o conteúdo originado é de interesse do seu utilizador, que ao fazer a busca, também consegue as informações do seu fabricante. (TREVISAN; MONTEIRO, 2017, p. 7). 
A estratégia de inbound marketing atende as unidades de informação perfeitamente por meio dos conteúdos direcionados tendo como objetivo a disseminação de informações relevantes para atrair e estabelecer um local de interação digital. Portanto, quando a informação é compartilhada e aceita, se transforma em conteúdo, ou seja, o processo da atração do público através de conteúdos tem como objetivo conquistar o consumidor e não o forçar a consumir seu produto/serviço, e é nessa ideia que o inbound marketing se baseia. No quadro a seguir, visualiza-se a comparação entre o outbound e o inbound marketing.

\section{Quadro 2 - Comparativo do Outbound Marketing e Inbound Marketing}

\begin{tabular}{|l|l|}
\hline \multicolumn{1}{|c|}{ OUTBOUND MARKETING } & \multicolumn{1}{c|}{ INBOUND MARKETING } \\
\hline $\begin{array}{l}\text { Propaganda direta por mídias de } \\
\text { massa }\end{array}$ & $\begin{array}{l}\text { Divulgação por conteúdo e fluxos de } \\
\text { nutrição }\end{array}$ \\
\hline Empresa vai até o cliente & Cliente vai até a empresa \\
\hline Marketing por interrupção & Marketing por atração \\
\hline Atinge em massa & Atinge um público segmentado \\
\hline Invasivo & Permissivo \\
\hline Investimento muito alto & Investimento baixo \\
\hline $\begin{array}{l}\text { Acessível a médias e grandes } \\
\text { empresas }\end{array}$ & $\begin{array}{l}\text { Acessível a pequenas, médias e } \\
\text { grandes empresas }\end{array}$ \\
\hline Engaja menos pessoas & Engaja mais pessoas \\
\hline Muito difícil de analisar os resultados & Mais fácil de analisar resultados \\
\hline
\end{tabular}

Fonte: Elaborado a partir do Portal ROCK CONTENT (2017).

O inbound marketing se destaca pela chegada da internet, e por este motivo, compreende-se que essa é uma estratégia focada em seus usuários devidamente segmentados, baseando-se sempre na interatividade e permissão dos usuários, em um ambiente participativo e acessível a comunidade das BUs.

Conforme discutido, mesmo que a biblioteca não obtenha lucros e não tenha prejuízo, isso não impede que ela trabalhe com estratégias de marketing.

É necessário que um conjunto de atividades administrativas promova o encontro, mutuamente satisfatório, entre as necessidades, desejos e expectativas do mercado que a biblioteca precisa atender e os objetivos organizacionais de longo prazo da própria biblioteca. (AMARAL, 1990, p. 313).

As bibliotecas também devem ter um planejamento de marketing eficaz, que acompanhe todas as atualizações do mercado para que seu público-alvo se sinta satisfeito e esteja sempre atualizado em relação aos serviços que ela dispõe; e o bibliotecário-mediador, é quem deve promover esse diferencial. 
O profissional da informação deve ter habilidades para fazer com que essas ações aconteçam da melhor maneira, para que o planejamento de marketing seja colocado em prática e seja visto como um fator importante para o sucesso da instituição. Amaral (1990, p. 315) afirma que "[...] o marketing contribui, beneficamente, para o desenvolvimento social, econômico, cultural e político da biblioteca, pois suas atividades respeitam os princípios legais e éticos vigentes e visam, prioritariamente, a satisfação do usuário." As bibliotecas ainda têm dificuldade de enxergar o marketing como o ponto chave para inovar a mediação da informação e alcançar seus objetivos.

Ao se utilizar das ferramentas do marketing digital, a biblioteca pode ser vista como uma organização presente na vida dos usuários e que pensa nas suas experiências. Por meio de novas estratégias de marketing, a instituição pode divulgar os serviços oferecidos ao seu público-alvo e atualizar seus usuários de cada novo serviço/produto que oferece por meio de um planejamento de marketing eficaz e eficiente.

\section{MEDIAÇÃO DA INFORMAÇÃO EM BIBLIOTECAS UNIVERSITÁRIAS NO ÂMBITO DIGITAL}

A mediação da informação é inerente no trabalho do bibliotecário, já que além do atendimento ao usuário, consiste em:

[...] toda ação de interferência - realizada em um processo, por um profissional da informação e na ambiência de equipamentos informacionais -, direta ou indireta; consciente ou inconsciente; singular ou plural, individual ou coletiva; visando a apropriação de informação que satisfaça, parcialmente e de maneira momentânea, uma necessidade informacional, gerando conflitos e novas necessidades informacionais.

A mediação não é estática, é caracterizada como uma interferência que depende do profissional da informação, seja ela de maneira implícita ou explícita, dependendo ou não da presença física dos usuários.

A mediação da informação sempre dependerá de uma dialogia, ou seja, da interação entre duas partes, seja de forma explícita ou implícita. Gomes (2014) afirma que a mediação da informação é um processo de compartilhamentos objetivo e intersubjetivo por meio dos quais os sujeitos envolvidos - bibliotecário e usuário - nesse compartilhamento sempre geram 
significações. Sendo assim, essa dialogia pode ser facilitada por novas ferramentas de interação na web, para ouvir e entender o usuário.

Este pensamento corrobora com o de Almeida Júnior (2009), ao dizer que o fazer bibliotecário pode basear-se na dialogia a fim de construir mecanismos que permitam aos usuários se apropriarem da informação, tanto nas atividades de interação indireta quanto nas de interação direta para facilitar o acesso e o uso da informação. Neste caso, a BU ao trabalhar com a informação em diferentes fases e com os mais diversos usuários e suas personalidades, deve se atentar que a informação mediada pelos profissionais da informação implica em como o usuário se apropria dela e como reage a novos conflitos, e também como participa do compartilhamento da informação.

As BUs são consideradas a alma das universidades e representam a essência bibliográfica e documental que subsidia o ensino, a pesquisa e a extensão (tripé das universidades), tendo como objetivo principal atender a comunidade acadêmica e orientar os usuários para que assim possam apropriarse da informação e construir conhecimento (SILVEIRA, 2009). Ressalta-se que as BUs vão muito além da disponibilização dos materiais impressos/digitais, elas oferecem a base do conhecimento universitário e muitas vezes se constituem como a principal fonte de informação para muitos usuários.

Por outro lado, lida-se com usuários de diversas gerações e muitos já nasceram imersos na área tecnológica e têm outro tipo de comportamento para se informar. Em vista disso, e de outros fatores, tanto o número de materiais em formato digital disponibilizados pelas BUs quanto o uso das Tecnologias de Informação e Comunicação (TIC) cresceram. Lopes e Silva (2006), afirmam que o avanço e a incorporação das TIC, principalmente da internet nas atividades das bibliotecas contribuem para a migração da filosofia de posse da informação para a filosofia do acesso, da mediação e apropriação da informação. As TIC contribuem para a inovação na mediação da informação e também no fazer do bibliotecário, auxiliando-o em suas tarefas para conquistar os objetivos na instituição e comunicação com os usuários.

O mediador da informação segundo Gomes (2014), age, constrói e interfere no meio, portanto, é um protagonista. O bibliotecário que exerce um 
papel de protagonista no processo de medição da informação não consegue ser neutro, imparcial e isento, ele exerce um papel fundamental para contribuição do conhecimento, ou mesmo, vai muito além disso, pois propicia um ambiente para gerar novos conflitos e novas perspectivas de outros assuntos em benefício da apropriação da informação e construção do conhecimento do usuário.

Ferreira (2004) ainda ressalta que os bibliotecários, especificamente os de referência, deverão integrar contextualmente as novas tecnologias, 0 instrumental da referência tradicional para as bibliotecas se tornarem competitivas no mercado informacional, o que possibilitará o fornecimento de informação com valor agregado. Nesse cenário, destaca-se a pesquisa realizada por Damian, Silva e Santos Neto (2021), em que os autores discutem as transformações no serviço de informação e referência frente ao contexto das bibliotecas híbridas e as possibilidades de mediações.

As BUs compõem no mercado competitivo informacional e com novas formas de mediação da informação por meio do inbound marketing, poderão resultar benefícios para a instituição a que estão vinculas e agregar valor aos serviços disponibilizados, além da participação e interatividade dos usuários na web social. Devido à participação do usuário, as BUs precisam estar inseridas em diferentes locais, além do serviço de referência da unidade de informação, como estar presente na internet, seja por meio de blogs, redes sociais, entre outros.

Resende (2011), destaca que os bibliotecários devem ir até seus usuários e também devem utilizar as diferentes possibilidades de comunicação como as redes sociais, por exemplo, e a criação de blogs para divulgar informações de forma mais direta, objetiva e atrativa para esse novo público. Santos e Gomes (2014, p. 40) afirmam que "[...] os dispositivos de comunicação promovem interferência direta na biblioteca e nas atividades de mediação da informação." Essas ferramentas contribuem para interagir com o usuário em um espaço, mesmo que virtual, mais acolhedor e menos inibidor à comunicação entre mediador e sujeito. As ferramentas facilitadoras à dialogia na mediação da informação, de acordo com Santos e Gomes (2014), são: Blogs e Microbloggings; Wikis; Tags; Chats; Redes Sociais e Sites de Compartilhamento, 
denominadas como Dispositivos de comunicação da Web 2.0.

As redes sociais como o Twitter, Facebook, YouTube e Flickr, Instagram, auxiliam a biblioteca a disponibilizar informações sobre sua rotina, divulgar serviços, interagir com os usuários instantaneamente. Essas ferramentas ampliam as possibilidades de comunicação com o usuário e destacam a participação do bibliotecário como mediador nesse processo.

Ao analisar os resultados obtidos nas buscas realizadas, foram identificadas muitas pesquisas que discutem o uso de ferramentas da web 2.0 ou web social por bibliotecas, e a seguir destaca-se algumas delas.

Brasileiro e Freire (2012) evidenciam que o Marketing se configura como disciplina complementar no desenvolvimento das ações de mediação da informação, caracterizadas pelo foco nos usuários, onde a primeira se volta para o planejamento e a gestão do processo mediacional.

Prado (2013) analisou o potencial estratégico em utilizar o Foursquare como um diferencial em bibliotecas. Como resultado, a pesquisa mostra que 0 uso de um aplicativo como o Foursquare, pode trazer à biblioteca uma maior visibilidade.

Brasil (2017) investigou as mediações deflagradas por uma biblioteca pública do Rio Grande do Sul sob a ótica do marketing e identificou esforços em prol de uma gestão eficiente, foco no cliente e promoção de ações culturais que visam, sobretudo, o seu reconhecimento na sociedade e seu local de destaque na comunidade.

Santos Neto e Almeida Júnior (2017) discutiram como as BUs podem utilizar o Facebook para mediar a informação e potencializar o alcance da divulgação dos serviços em universidades estaduais paranaenses. A análise mostra que as unidades de informação estão se atentando cada vez mais às formas de comunicação existentes na web e que há uma interação entre elas e seus usuários.

Vaz e Venâncio (2018) discutem o marketing, a difusão, a ação cultural e a mediação como formas para um equipamento informacional - arquivos públicos - alcançar seus objetivos. Destacam que para isso é fundamental que os profissionais e mediadores compreendam a verdadeira significância e 
abrangência desses termos.

Além das pesquisas publicadas, há também outras fontes de informação que orientam e têm ajudado muitos profissionais tanto a entender conceitos básicos de marketing quanto a empregá-los profissionalmente. Como exemplo, cita-se o caso da bibliotecária Mayara Cabral Cosmo, que possui Especialização em MBA em Comunicação e Marketing em Mídias Digitais e é mestranda em Ciência da Informação. Mayara Cabral é mantenedora do perfil no Instagram @biblio.mkt, que tem a finalidade produzir conteúdos educativos sobre marketing para bibliotecas e profissionais de Biblioteconomia nas principais plataformas de mídias sociais digitais, enfocando sobretudo nos quesitos: posicionamento, conteúdo e estratégia.

Essas pesquisas e relatos ressaltam a importância das estratégias de marketing e das ferramentas disponíveis na internet para ajudar as BUs a se comunicar melhor com seus usuários, permitindo ao usuário acadêmico ter mais um espaço - mesmo que virtual - para acessar a informação. Ressalta-se que assim como essas ações e ferramentas são importantes para o usuário, também são importantes para a mediação da informação das BUs, pois lida-se com a interferência direta do bibliotecário, interação com o usuário e seu feedback. Com essas estratégias, outro beneficiado com as ferramentas da web é o bibliotecário, o profissional pode, a partir das suas habilidades e competências, ampliar sua rede de comunicação e alcançar mais usuários, além de contribuir com o objetivo da instituição de mediar informação à comunidade. No entanto, compete ao profissional da informação ser o protagonista dessa dialogia, cabe a ele analisar estratégias e recursos para colocar essas ações em prática e cumprir com o seu protagonismo na mediação da informação.

Prado e Correa (2016, p. 168), corroboram o exposto ao afirmar que "[...] a presença digital de qualquer organização é efetiva quando se aliam suas ferramentas, espaços e estratégias das quais dispõem." Sendo assim, as BUs não precisam enxergar as novas ferramentas disponíveis na internet como uma concorrente e/ou substituta, mas como ferramentas aliadas ao processo de mediação da informação, que auxiliam dentro e fora do ambiente físico; devem enxergar redes sociais, blogs, websites, entre outros como uma aproximação ao 
seu público e formas de interação facilitadoras à mediação da informação favorecendo a apropriação da informação dos sujeitos inseridos no processo de mediação.

\section{CONSIDERAÇÕES FINAIS}

Mediar informação é algo que está imbricado ao cotidiano do profissional da informação, ou seja, é inerente ao fazer do bibliotecário. As bibliotecas universitárias e seus mediadores podem adotar o inbound marketing para potencializar a mediação da informação na web de distintas formas. Destaca-se que saber como utilizar dispositivos midiáticos e conhecer as funcionalidades das redes e mídias sociais, para que a comunicação da biblioteca seja rápida e precisa é fundamental para que os bibliotecários possam aproximar as instituições de seus usuários. Atualmente, além do YouTube, Facebook, Instagram, por exemplo, incidem o TikTok e o Reels (nova funcionalidade do Instagram).

Além de fazer parte da gestão das bibliotecas, considera-se essencial que o marketing seja inserido nas matrizes curriculares dos cursos de graduação em Biblioteconomia, visando o desenvolvimento das competências do profissional da informação para atuar nessa área. O conhecimento que o profissional tem sobre a comunicação e as ações que podem ser realizadas para atrair os usuários geram valor ao produto/serviço que a biblioteca oferece a sociedade, logo, a imagem e a percepção que os usuários terão da unidade e dos profissionais que nela atuam será alterada.

As possibilidades de formação continuada através dos cursos de especialização, MBAs, consultorias, palestras, oficinas e workshops (minicursos) com profissionais da área de marketing são soluções para amenizar a falta de profissionais qualificados para trabalhar com essas ações de inbound marketing nas BUs. Além disso, investir na capacitação do profissional e reconhecer suas competências, geram valor ao serviço informacional das BUs.

Considera-se que conhecer estratégias contemporâneas de marketing, como o inbound marketing, permitem a prospecção de novas formas de mediação da informação para potencializar os produtos e serviços 
informacionais das BUs. Conclui-se que o protagonismo do bibliotecário, a estratégia de inbound marketing junto à mediação da informação se estabelece como uma tríade para que as bibliotecas universitárias não paralisem no tempo em meio às TIC e que sejam essenciais para o futuro da sociedade, assim como foi, ainda é e será.

\section{REFERÊNCIAS}

ALMEIDA JÚNIOR, O. F. Mediação da informação: um conceito atualizado. In: BORTOLIN, S.; SANTOS NETO, J. A.; SILVA, R. J. (org.). Mediação oral da informação e da leitura. Londrina: ABECIN, 2015. p. 9-32.

ALMEIDA JÚNIOR, O. F. Mediação da informação e múltiplas linguagens. Tendências da Pesquisa Brasileira em Ciência da Informação, v. 2, n. 1, p. 89-103, jan./dez. 2009. Disponível em:

https://revistas.ancib.org/index.php/tpbci/article/view/170. Acesso em: 18 abr. 2021.

AMARAL, S. A. Marketing e gerência de biblioteca. Revista de Biblioteconomia de Brasília, v. 18, n. 2, p. 311-317, 1990. Disponível em: http://www.brapci.inf.br/v/a/8490. Acesso em: 18 abr. 2021.

BRASIL, C. A. S. Biblioteca pública, marketing e mediação: um estudo de caso na Biblioteca Pública Municipal Fernandes Bastos, em Osório/Rs. 2017. 79f. Trabalho de Conclusão de Curso (Graduação em Biblioteconomia) Faculdade de Biblioteconomia e Comunicação, Universidade Federal do Rio Grande do Sul, 2017. Disponível em:

https://www.lume.ufrgs.br/handle/10183/175279. Acesso em: 18 abr. 2021.

BRASILEIRO, F. S.; FREIRE, G. H. A. O marketing e a arquitetura da informação para web no contexto do processo de mediação da informação. Biblionline, João Pessoa, v. 8, n. esp., p. 161-174, 2012. Disponível em: https://periodicos.ufpb.br/ojs/index.php/biblio/article/view/14200/8106. Acesso em: 18 abr. 2021.

CANECA, J. A. Qual é a diferença entre marketing de conteúdo e Inbound Marketing? 2015. Disponível em:

http://blog.aotopo.com.br/?s=0+que+\%C3\%A9++inbound+marketing. Acesso em: 18 abr. 2021.

DAMIAN, I. P. M.; SILVA, R. C.; SANTOS NETO, J. A. Serviço de referência e informação no contexto da hibridez em bibliotecas. RDBCl: Revista Digital de Biblioteconomia e Ciência da Informação, Campinas, SP, v. 19, n. 00, p. e021007, 2021. DOI: 10.20396/rdbci.v19i00.8664478. Disponível em: 
https://periodicos.sbu.unicamp.br/ojs/index.php/rdbci/article/view/8664478.

Acesso em: 18 abr. 2021.

FERREIRA, M. I. G. High tech/high touch: serviço de referência e mediação humana. In: CONGRESSO NACIONAL DE BIBLIOTECÁRIOS, ARQUIVISTAS E DOCUMENTALISTAS, 8., 2004, Estoril. Actas eletrónicas... Disponível em: http://badinfo.apbad.pt/congresso8/com29.pdf. Acesso em: 18 abr. 2021.

GABRIEL, M. Marketing na era digital: conceitos, plataformas e estratégias. São Paulo: Novatec. 2010.

GIL, A. C. Como elaborar projetos de pesquisa. 4. ed. São Paulo: Atlas, 2002.

GOMES, H. F. A dimensão dialógica, estética, formativa e ética da mediação da informação. Informação \& Informação, Londrina, v. 19, n. 2, p. 46-59, out. 2014. Disponível em:

http://www.uel.br/revistas/uel/index.php/informacao/article/view/19994/19090. Acesso em: 18 abr. 2021.

KOTLER, P. Administração de marketing: análise, planejamento, implementação e controle. 5 ed. São Paulo: Atlas 1998.

KOTLER, P.; KELLER, K. L. Administração de marketing. 12. ed. São Paulo: Pearson Hall, 2006.

LAS CASAS, A. L. Marketing de serviços. 5. Ed. São Paulo: Atlas, 2007, $257 p$.

LOPES, M.; SILVA, E. L. As bibliotecas universitárias e a mediação da informação na comunicação científica. In: SEMINÁRIO NACIONAL DE BIBLIOTECAS UNIVERSITÁRIAS, 14., 2006, Salvador. Anais eletrônicos... Salvador: UFBA, 2006. Disponível em: http://www.snbu2006.ufba.br/soac/viewabstract.php?id=105. Acesso em: 18 abr. 2021.

RESULTADOS DIGITAIS. Inbound Marketing. 2016. Disponível em: https://resultadosdigitais.com.br/especiais/inbound-marketing/. Acesso em: 18 abr. 2021.

PRADO, J. M. K. O Foursquare em bibliotecas: um diferencial estratégico em marketing. Revista ACB, Florianópolis, v. 18, n. 1, p. 846-855, out. 2012.

Disponível em: https://revista.acbsc.org.br/racb/article/view/879. Acesso em: 18 abr. 2021.

PRADO, J. M. K.; CORREA, E. C. D. Bibliotecas universitárias e presença digital: estabelecimento de diretrizes para o uso de mídias sociais.

Perspectivas em Ciência da Informação, Belo Horizonte, v. 21, n. 3, p. 165181, Set. 2016. Disponível em:

http://www.scielo.br/scielo.php?script=sci_arttext\&pid=S1413-

99362016000300165\&lng=en\&nrm=iso. Acesso em: 18 abr. 2021. 
PRADO, J. M. K.; PINTO, A. L. Marketing na Ciência da Informação brasileira: quatro décadas de produção. Informação \& Sociedade: Estudos, João Pessoa, v. 28, n. 3, p. 53-68, set./dez. 2018. Disponível em: https://periodicos.ufpb.br/ojs2/index.php/ies/article/view/37935/21800. Acesso em: 18 abr. 2021.

RESENDE, E. S. O bibliotecário e a evolução do serviço de referência na biblioteca universitária. In: CONGRESSO BRASILEIRO DE BIBLIOTECONOMIA, DOCUMENTAÇÃO E CIÊNCIA DA INFORMAÇÃO, 24. 2011, Maceió. Anais eletrônicos... Maceió: Febab, 2011. Disponível em: http://pantheon.ufrj.br/handle/11422/3071. Acesso em: 18 abr. 2021.

ROCHA, E. S. S.; RODRIGUES, R. M.; RODRIGUES, V. Marketing digital em bibliotecas digitais: um estudo sobre a aplicabilidade de ferramentas da Web 2.0. In: CONGRESSO BRASILEIRO DE BIBLIOTECONOMIA, DOCUMENTO E CIÊNCIA DA INFORMAÇÃO, 15., 2013, Florianópolis. Anais eletrônicos... Florianópolis: FEBAB, 2013. Disponível em https://portal.febab.org.br/anais/article/view/1307/1308. Acesso em: 18 abr. 2021.

ROCK CONTENT. Inbound marketing $\mathbf{x}$ outbound marketing: quem ganha? 2017. Disponível em: https://marketingdeconteudo.com/inbound-marketingxoutbound-marketing/. Acesso em: 18 abr. 2021.

SANTOS, R. R. Espaço virtual e a comunicação com os usuários para a mediação da informação: utilização pelas bibliotecas das universidades federais e estaduais brasileiras. 2012. 248f. Dissertação (Mestrado em Ciência da Informação) - Universidade Federal da Bahia, Instituto de Ciência da Informação, Salvador. Dísponível em: http://repositorio.ufba.br/ri/handle/ri/7833. Acesso em: 18 abr. 2021.

SANTOS, R. R.; GOMES, H. F. Utilização dos dispositivos de comunicação da web social pelas bibliotecas universitárias: um espaço para mediação da informação. Transinformação, Campinas, v. 26, n. 1, p. 39-50, jan/abr, 2014. Disponível em: http://www.scielo.br/pdf/tinf/v26n1/a05. Acesso em: 18 abr. 2021.

SANTOS NETO, J. A.; ALMEIDA JÚNIOR, O. F. Bibliotecas universitárias das instituições estaduais de ensino superior paranaenses e a mediação da informação no Facebook. RDBCI: Revista Digital de Biblioteconomia e Ciência da Informação, v. 15, n. 2, p. 442-468, 2017. Disponível em: http://eprints.rclis.org/31863/. Acesso em: 18 abr. 2021.

SILVEIRA, D. T.; CÓRDOVA, F. P. A pesquisa científica. In: GERHARDT, T. E.; SILVEIRA, D. T. Métodos de pesquisa. Porto Alegre: Editora da UFRGS, 2009. p. 31-42. Disponível em: http://www.ufrgs.br/cursopgdr/downloadsSerie/derad005.pdf. Acesso em: 18 abr. 2021. 
SILVEIRA, J. G. Gestão de recursos humanos em bibliotecas universitárias: reflexões. Ciência da Informação, Brasília, v. 38, n. 2, p. 126-141, ago. 2009. Disponível em: http://www.scielo.br/scielo.php?script=sci_arttext\&pid=S010019652009000200010\&lng=en\&nrm=iso . Acesso em: 18 äbr. 2021.

TREVISAN, G. L.; MONTEIRO, S. D. O marketing de conteúdo, o inbound marketing e suas confluências à ciência da informação. In: SEMINÁRIO EM CIÊNCIA DA INFORMAÇÃO, 7., 2017, Londrina. Anais eletrônicos... Londrina: UEL, 2017. Disponível em:

http://www.uel.br/eventos/cinf/index.php/secin2017/secin2107/paper/viewFile/4 20/322. Acesso em: 18 abr. 2021.

VARANDA, L. I. A. Inbound marketing: estudo sobre a percepção da credibilidade da fonte em comunidades online. 2010. Dissertação (Mestrado em Marketing) - ISCTE Business School, Instituto Universitário de Lisboa, 2010. Disponível em: http://hdl.handle.net/10071/3269. Acesso em: 18 abr. 2021.

VAZ, G. A.; VENÂNCIO, R. P. Marketing, difusão, ação e mediação cultural em arquivos públicos. RACIn, João Pessoa, v. 6, n. 1, p. 01-29, jan./jun. 2018.

Disponível em:

http://arquivologiauepb.com.br/racin/edicoes/v6_n1/racin_v6_n1_artigo01.pdf. Acesso em: 18 abr. 2021.

\title{
INBOUND MARKETING IN LIBRARIES: NEW FORMS OF INFORMATION MEDIATION
}

\begin{abstract}
Objective: To discuss how university libraries can adopt inbound marketing to enhance the mediation of information. Methodology: The research is of a basic nature and exploratory typology, employs a qualitative approach and follows the bibliographic outline from the literature specialized in Information Science and Marketing, published in the main databases and information sources, namely: CAPES Journals Portal, Information Science Database (BRAPCI), Scielo and Google Scholar. Results: Inbound marketing strategies support the interaction of libraries with their users in a more direct and effective way and are also important for the mediation of information. Conclusions: Knowing contemporary marketing strategies, such as inbound marketing, allow the prospecting of new forms of mediation of information to enhance the informational products and services of BUs.
\end{abstract}

Descriptors: Marketing in libraries. Inbound marketing. University Libraries. Information mediation.

\section{INBOUND MARKETING EN BIBLIOTECAS UNIVERSITARIAS: NUEVAS FORMAS DE MEDIACIÓN DE LA INFORMACIÓN}




\section{RESUMEN}

Metodología: La investigación es de carácter básico y tipología exploratoria, emplea un enfoque cualitativo y sigue el esquema bibliográfico de la literatura especializada en Ciencias de la Información y Marketing, publicada en las principales bases de datos y fuentes de información, a saber: Portal de Periódicos da CAPES, Información Science Database (BRAPCI), Scielo y Google Scholar. Resultados: Las estrategias de Inbound Marketing apoyan la interacción de las bibliotecas con sus usuarios de una manera más directa y efectiva y también son importantes para la mediación de la información. Conclusiones: Conocer las estrategias de marketing contemporáneas, como el inbound marketing, permite la perspectiva de nuevas formas de mediación de la información para potenciar los productos y servicios de información de las BU.

Descriptores: Marketing en bibliotecas. Inbound marketing. Bibliotecas Universitarias. Mediación de la información.

Recebido em: 19.04 .2021

Aceito em: 30.04.2021 